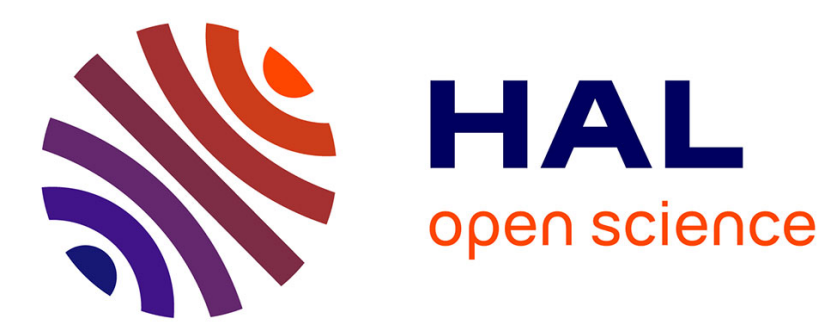

\title{
Factors affecting log traits and green rotary-peeled veneer recovery from temperate eucalypt plantations
}

\author{
Matthew G. Hamilton, David P. Blackburn, Robert L. Mcgavin, Henri \\ Baillères, Mario Vega, Brad M. Potts
}

\section{- To cite this version:}

Matthew G. Hamilton, David P. Blackburn, Robert L. Mcgavin, Henri Baillères, Mario Vega, et al.. Factors affecting log traits and green rotary-peeled veneer recovery from temperate eucalypt plantations. Annals of Forest Science, 2015, 72 (3), pp.357-365. 10.1007/s13595-014-0430-0 . hal01284182

\section{HAL Id: hal-01284182 \\ https://hal.science/hal-01284182}

Submitted on 7 Mar 2016

HAL is a multi-disciplinary open access archive for the deposit and dissemination of scientific research documents, whether they are published or not. The documents may come from teaching and research institutions in France or abroad, or from public or private research centers.
L'archive ouverte pluridisciplinaire HAL, est destinée au dépôt et à la diffusion de documents scientifiques de niveau recherche, publiés ou non, émanant des établissements d'enseignement et de recherche français ou étrangers, des laboratoires publics ou privés. 


\title{
Factors affecting log traits and green rotary-peeled veneer recovery from temperate eucalypt plantations
}

\author{
Matthew G. Hamilton • David P. Blackburn • \\ Robert L. McGavin • Henri Baillères • Mario Vega • \\ Brad M. Potts
}

Received: 28 July 2014 / Accepted: 3 October 2014 / Published online: 6 November 2014

(C) INRA and Springer-Verlag France 2014

\begin{abstract}
- Key message High levels of percentage green veneer recovery can be obtained from temperate eucalypt plantations. Recovery traits are affected by site and log position in the stem. Of the post-felling log traits studied, outof-roundness was the best predictor of green recovery.

- Context Eucalyptus globulus and Eucalyptus nitens are widely planted in temperate regions of the globe but few studies of rotary peeling have been documented.

- Aims This study aims to examine differences among sites and $\log$ positions in post-felling log traits and green veneer recovery traits and determine the extent to which log traits explain variation in recovery traits.
\end{abstract}

\section{Handling Editor: Jean-Michel Leban}

Contribution of the co-authors All authors undertook writing/editing the manuscript and all, except Brad Potts, were involved in data collection. Matthew Hamilton oversaw the selection, felling and transport of logs, undertook statistical analyses and wrote the first draft of the manuscript. Robert McGavin and Henri Bailleres oversaw the peeling of logs.

Electronic supplementary material The online version of this article (doi:10.1007/s13595-014-0430-0) contains supplementary material, which is available to authorized users.

M. G. Hamilton $(\bowtie) \cdot$ D. P. Blackburn • M. Vega $\cdot$ B. M. Potts

School of Biological Sciences, University of Tasmania (UTAS),

Private Bag 55, Hobart, Tasmania 7000, Australia

e-mail: Matthew.Hamilton@utas.edu.au

D. P. Blackburn

e-mail: david.blackburn@utas.edu.au

M. Vega

e-mail:mhvega@utas.edu.au

B. M. Potts

e-mail: b.m.potts@utas.edu.au

M. G. Hamilton • D. P. Blackburn • R. L. McGavin • H. Baillères • M. Vega $\cdot$ B. M. Potts

National Centre for Future Forest Industries, Private Bag 55, Hobart,

Tasmania 7001, Australia
- Methods Log traits and green rotary-peeled veneer recovery traits from six temperate eucalypt plantations were studied. Selected plantations encompassed different age, site productivity, silvicultural and species classes in south-eastern Australia. Differences in log and recovery traits among sites and between lower and upper logs were examined, as was the extent to which log traits explained variation in recovery traits. - Results Differences among sites for percentage recovered green veneer were non-significant, despite significant differences for peelable billet volume, roundup loss, residual core diameter and all post-felling log traits: small end diameter, sweep, taper, out-of-roundness, end splitting and dynamic modulus of elasticity $\left(\mathrm{MOE}_{\mathrm{dyn}}\right)$. The lower log exhibited more sweep, taper and out-of-roundness but lower $\mathrm{MOE}_{\mathrm{dyn}}$ and less recovered green veneer. Out-of-roundness was the best predictor of recovery traits $\left(R^{2}=13-21 \%, P<0.001\right)$.

- Conclusion Recovered green veneer was high across all sites and $\log$ positions ( $78 \%$ overall).

Keywords Eucalyptus globulus $\cdot$ Eucalyptus nitens . Site effect $\cdot \log$ position $\cdot \log$ characteristics

\author{
R. L. McGavin \\ e-mail: robbie.mcgavin@daff.qld.gov.au \\ H. Baillères \\ e-mail: henri.bailleres@daff.qld.gov.au
}

R. L. McGavin

Department of Forest Ecosystem Science, University of Melbourne, 500 Yarra Boulevard, Richmond, Victoria 3121, Australia

R. L. McGavin · H. Baillères

Queensland Department of Agriculture, Fisheries and Forestry, Horticulture and Forestry Science, Salisbury Research Facility, 50 Evans Road, Salisbury, Queensland 4107, Australia 


\section{Introduction}

Eucalyptus globulus and Eucalyptus nitens are widely planted in Australia, Chile, Spain, Portugal and South Africa and are primarily managed as unthinned and unpruned stands for pulpwood. However, sizable areas of plantation have been thinned and pruned, targeting clearwood (i.e. knot-free) logs for the production of decorative sawn timber and face veneer. For example, in Tasmania, Australia, approximately 26000 ha of predominantly $E$. nitens plantation is managed under such regimes (Wood et al. 2009). E. globulus is generally regarded as superior to E. nitens in terms of its kraft-pulping properties (Downes et al. 2006; Kibblewhite et al. 2000), strength, stiffness and hardness (McKinley et al. 2002; Potts et al. 2011) but E. nitens is more cold tolerant (Wardlaw 2011) and is less susceptible to Mycosphaerella leaf disease (Mohammed et al. 2003).

In the Australian context, the potential of the standing hardwood plantation resource as a feedstock for processes and products other than pulpwood is not well understood, as the bulk of the hardwood plantation estate was established relatively recently. This is exemplified by a dearth of studies examining the potential for the production of rotary-peeled veneer from either E. globulus or E. nitens (Blakemore et al. 2010; Blackburn et al. 2012; Farrell et al. 2011; McGavin et al. 2014). In several Asian countries, small-diameter unthinned and unpruned eucalypt logs are rotary peeled, generally by small-scale processors in regions with low labour costs (McGavin et al. 2014; Arnold et al. 2013; Luo et al. 2013). Alternative uses for the E. globulus and E. nitens plantation resource are of interest to growers and processors as a means of increasing grower returns and establishing profitable processing industries (Washusen et al. 2009; Washusen 2011; McGavin et al. 2014).

Although the value of veneer products is ultimately determined by grade recovery and utility after drying, maximising the recovery of green veneer from billets is a fundamentally important consideration in maximising the profitability of rotary peeling operations (Shi and Walker 2006). Green veneer recovery can be expressed as the recovered percentage of the green billet volume, prior to billet roundup and peeling. Billet roundup is the first step in rotary peeling, where irregularly shaped billets are machined to a cylindrical peeler block. No useable veneer is recovered during roundup. Once billets are cylindrical, they are peeled to recover green veneer down to a residual core (i.e. the peelable volume of a $\log$ is represented by a hollow cylinder). Accordingly, green recovery is maximised when roundup loss and residual core diameter are minimised. Log characteristics affecting roundup loss and residual core diameter are different. Post-felling log traits such as small end diameter under bark, sweep, taper, and outof-roundness might be expected to impact on roundup loss (McGavin et al. 2014; Luo et al. 2013), and factors affecting wood integrity and strength, such as log end splitting and wood decay (incipient or advanced), are likely to directly affect residual core diameter.

The specific objectives of this study were to determine the following:

- If there are differences among sites in post-felling log traits, including small end diameter under bark, sweep, taper, out-of-roundness, end splitting and dynamic modulus of elasticity

- If there are differences among sites in green veneer recovery traits, including peelable billet volume, recovered green veneer, roundup loss and residual core diameter

- Whether differences among sites are stable regardless of billet position

- The extent to which post-felling log traits explain variation in recovery traits

Appropriately matching plantation species, silviculture and environment to processes and products has the potential to unlock previously unidentified value in the standing plantation resource. The findings of this study will inform decisions regarding standing resource utilisation, plantation research and ultimately species selection, site selection, forest management and product use optimisation.

\section{Materials and methods}

Trees for the study were sourced from six temperate eucalypt plantations located in south-eastern Australia near Strathblane, Geeveston and Florentine Valley in Tasmania and Deans Marsh, Orford and Mumbannar in Victoria. These plantations were selected to represent a range of environments and silvicultural regimes under which temperate eucalypt plantations are grown. Florentine Valley (E. nitens), Orford (E. globulus) and Mambannar (E. globulus) represented harvest-age pulpwood stands, and Strathblane (E. nitens), Geeveston (E. nitens) and Deans Marsh (E. globulus) represented thinned and pruned stands, although none had yet reached their notional harvest age of 25-30 years. The age at which individual plantations are commercially harvested is a function of growth rates and economic parameters.

Basal area plots were established in each plantation from which study trees for rotary peeling were selected at random. To avoid the selection of severely suppressed trees and to meet the splindeless lathe diameter requirements, trees at most sites that were less than 220 or greater than $390 \mathrm{~mm}$ in diameter at breast height over bark (DBHOB; $1.3 \mathrm{~m}$ ) were excluded. Trees with ramicorns, double leaders, major branches or visible external injuries that would have precluded peeling were also excluded. At the Geeveston site, where average tree diameter was greatest, the maximum diameter criterion for 
the spindleless lathe was relaxed. The number of trees sampled, location, species, silviculture, environmental characteristics, genetic origins, year of planting and felling method for each site are detailed in Online Resource 1.

Two 2-m logs were cut from each tree on the same day as felling - one from 0.5 to $2.5 \mathrm{~m}$ and the other from 3.7 to $5.7 \mathrm{~m}$ from the base of each stem. Logs were transported to one of two log yards - Geeveston (Tasmania) or Hamilton (Victoria)-for debarking, measurement and loading into a shipping container for transport to the Salisbury Timber Research Facility in Brisbane.

Large-end-diameter under bark (LEDUB) and small-enddiameter under bark (SEDUB) were assessed on each log using a diameter tape. Log taper was estimated as the difference between LEDUB and SEDUB divided by the log length. In addition, the minimum and maximum SEDUB and LEDUB were measured through the centre of the $\log$ (i.e. ignoring the position of the pith) using a steel rule and out-ofroundness estimated for each log end as the difference between the minimum and maximum diameter divided by the average of the minimum and maximum diameter (Warensjo and Rune 2004). Log end estimates of out-of-roundness were then averaged for each log. Log sweep was measured as the maximum deviation from a taut string, bridging the log ends, to the $\log$ surface. Log end splitting was assessed approximately $24 \mathrm{~h}$ after cross cutting according to the 'Split Index 2' method outlined in Yang (2005):

Idividual splitindex $=\frac{\frac{\mathrm{SL}_{\mathrm{END}}^{2}}{2}+\mathrm{SL}_{\mathrm{SUFRACE}} * \mathrm{SL}_{\mathrm{END}}}{R^{2}}$

where $\mathrm{SL}_{\mathrm{END}}$ is the split length on the log end, $\mathrm{SL}_{\mathrm{SURFACE}}$ is the split length on the $\log$ surface and $R$ is the mean radius under bark of the log end. The Log Split Index was calculated as the sum of all individual split indices for each log.

Logs were kept damp prior to transport to the Salisbury Timber Research Facility. Upon arrival, longitudinal acoustic vibration measurements were captured on all logs using the CIRAD Bing ${ }^{\circledR}$ device to allow estimation of dynamic modulus of elasticity (Brancheriau and Bailleres 2002). Two-metre logs were then docked to produce $1.3-\mathrm{m}$ peeler billets. At the time of docking, cross-cuts were positioned to minimise end splitting in peeler billets (i.e. the position of cross cuts varied among billets) and the expression of splitting in veneer sheets. After docking, SEDUB and LEDUB were reassessed using a diameter tape and billet volume was estimated according to Smalian's formula - the billet length $(1.3 \mathrm{~m})$ multiplied by the average of the areas of the two billet ends.

Billet roundup and peeling was undertaken using an OMECO spindleless veneer lathe model TR4 (McGavin et al. 2014). The time between felling and peeling ranged from 14 to 30 days. Twelve billets from the Geeveston site were too large to be peeled with the spindleless lathe ( $>400 \mathrm{~mm}$ LEDUB). These logs were rounded and/or partially peeled using a conventional spindled lathe prior to docking and peeling using the same procedure outlined for other billets.

Billet diameters were measured with a tape after roundup and prior to the peeling of a veneer ribbon with a targeted thickness of $2.8 \mathrm{~mm}$. The width of the veneer ribbon (perpendicular to the grain) and the diameter of the residual billet core were measured. The mean veneer thickness for each billet was calculated from green veneer thickness measured using a dial thickness gauge with a nominal precision of $0.01 \mathrm{~mm}$. Thickness was assessed at three points along the length (ends and midpoint) of 150-mm-wide samples clipped from the veneer ribbon between full veneer sheets which were nominally $1400 \mathrm{~mm}$ wide (McGavin et al. 2014).

'Peelable billet volume' was estimated as the difference between rounded up billet volume and residual core volume, both of which were estimated, assuming they were cylinders, from measured diameters and billet length (Online Resource 2). Recovered green veneer volume was estimated for each billet as the product of billet mean green veneer thickness, ribbon width and billet length. Roundup loss was calculated as the difference between total billet volume and rounded up billet volume. Peelable billet volume, recovered green veneer volume and roundup loss were expressed as a percentage of total billet volume for analyses.

The minimum residual core diameter was $49 \mathrm{~mm}$ and the maximum $123 \mathrm{~mm}$ but the majority of billets, 139 of 201 peeled, had a core diameter within $\pm 1 \mathrm{~mm}$ of $50 \mathrm{~mm}$. Accordingly, logs were partitioned into one of two categories: those that were deemed to have been peeled to the targeted residual core diameter (i.e. $50 \pm 1 \mathrm{~mm}$; 'target-sized') and those that were not (i.e. $>51 \mathrm{~mm}$; 'over-sized'). Possible causes of oversized residual cores include the presence of splits, decay and concentration of strength reducing defects, such as knots, in billets.

\subsection{Statistical analyses}

To examine the effects of site and log position on post-felling $\log$ traits (SEDUB, sweep, taper, out-of-roundness, end splitting and dynamic modulus of elasticity $\left.\left(\mathrm{MOE}_{\mathrm{dyn}}\right)\right)$ and the three green recovery traits expressed as a percentage of log volume (peelable billet volume, recovered green veneer volume and roundup loss), the SAS ${ }^{\mathrm{TM}}$ Proc Mixed procedure for repeated measures (Wolfinger and Chang 1995) was used. A fixed-effect model was fitted including site, log position and their interaction as explanatory variables. As trees represented independent experimental units and measurements on billets represented repeated measures of traits on these independent experimental units, tree was fitted as the subject effect and an unstructured within-subject variance covariance matrix was 
assumed. Data were transformed in cases where residuals exhibited heteroscedasticity and/or deviated from the assumption of normality (Online Resource 2). The green recovery trait of residual core diameter was analysed as a binary variable, fitting the same model terms as for the other traits, with a logit link function using the SAS ${ }^{\mathrm{TM}}$ Proc Glimmix procedure, as residuals could not be normalised using other forms of transformation.

To examine the extent to which post-felling log traits explained variation across sites and log positions, regression analyses were undertaken fitting recovery traits, except residual core diameter, as response variables and log traits as explanatory variables. Only post-felling log traits for which there was an a priori hypothesis that they affect the recovery trait were included as explanatory variables (Table 1). Univariate and multiple regression analyses were undertaken using the SAS ${ }^{\mathrm{TM}}$ Proc Reg procedure. Individual simple linear regression analyses were undertaken for all combinations of explanatory variable and response variable. Furthermore, regression analyses were repeated using standardised log and recovery data - where data for each log and recovery trait were standardised to have a mean of zero and standard deviation of one within each combination of site and log position. Regression analyses based on standardised data were used to gauge the extent to which log characteristics explained variation in recovery traits within a site and log position cohort, in contrast to analyses based on the non-standardised data which did not account for the origin of logs.

Regression analyses were not undertaken for the binary recovery trait of residual core diameter. Instead, the effect of the post-felling log traits SEDUB, end splitting and $\mathrm{MOE}_{\mathrm{dyn}}$ on core diameter was gauged by testing the difference in the mean of target-sized and over-sized cores for these traits with two-way $t$ tests.

\section{Results}

\subsection{Differences among sites and log positions}

Significant differences were observed among plantation sites in all post-felling log traits (Table 2) - SEDUB was greatest at

Table 1 Response and explanatory variables included in regression analyses

\begin{tabular}{ll}
\hline $\begin{array}{l}\text { Response variable } \\
\text { (recovery trait) }\end{array}$ & Explanatory variables (log traits) \\
\hline $\begin{array}{c}\text { Peelable billet volume } \\
(\%)\end{array}$ & $\begin{array}{c}\text { SEDUB, sweep, taper, out-of-roundness, end } \\
\text { splitting and } \mathrm{MOE}_{\mathrm{dyn}}\end{array}$ \\
$\begin{array}{c}\text { Recovered green } \\
\text { veneer (\%) }\end{array}$ & $\begin{array}{c}\text { SEDUB, sweep, taper, out-of-roundness, end } \\
\text { splitting and MOE }\end{array}$ \\
Roundup loss $(\%)$ & SEDUB, sweep, taper and out-of-roundness \\
\hline
\end{tabular}

Geeveston, sweep greatest at Orford, taper and out-ofroundness greatest at Deans Marsh, end splitting greatest at Geeveston and Orford and $\mathrm{MOE}_{\text {dyn }}$ greatest at Orford (Fig. 1). There were significant differences between the upper and lower $\log$ s for all $\log$ traits except end splitting (Table 2, Fig. 1e). Across the sites, the lower log exhibited the greatest SEDUB, taper, out-of-roundness and sweep but the upper log had greater $\mathrm{MOE}_{\mathrm{dyn}}$ (Table 2).

A significant $(P<0.05)$ site by log interaction effect was evident in SEDUB, out-of-roundness, end splitting and $\mathrm{MOE}_{\text {dyn }}$ (Table 2). However, the $F$ ratios associated with the main effects of site and log position were, for the most part, substantially greater than those for the interaction in these traits, and the ranking of the lower and upper log was generally consistent across sites (Fig. 1a, d-f). Exceptions to these general observations were the $F$ ratio for the effect of $\log$ position on end splitting, which was exceptionally low and non-significant (Table 2; Fig. 1e) and the ranking of log positions for out-of-roundness at Deans Marsh (Fig. 1d). There was a greater difference between the upper and lower $\log$ for out-of-roundness (Fig. 1d) at E. nitens sites than there was at E. globulus sites.

For the recovery traits, a significant difference between the upper and lower log was present in all but residual core diameter class (Table 2). Across the sites, the upper log had the greatest peelable billet volume (\%) and recovered green veneer (\%), and the lower log exhibited the greatest roundup loss (\%). There was no significant difference among sites in recovered volume of green veneer but there were significant differences among sites in peelable billet volume, roundup loss and residual core diameter. No significant interactions between site and $\log$ position were evident for the recovery traits.

\subsection{Post-felling log traits as predictors of recovery}

Across sites and $\log$ positions (i.e. using nonstandardised data), simple linear regression analyses indicated that both taper and out-of-roundness significantly explained variation in peelable billet volume, recovered green veneer and roundup loss (Table 3). Sweep also significantly explained variation in peelable billet volume and roundup loss. Increases in sweep, taper and out-of-roundness were associated with decreased peelable billet volume and recovered green volume and increased roundup losses. Between 13.0 and $20.8 \%$ of recovery traits was explained by outof-roundness alone. Furthermore, multiple regression analyses revealed that out-of-roundness and sweep together explained $23.5 \%$ of variation in peelable billet volume, $13.5 \%$ in recovered green veneer and $26.8 \%$ in roundup loss. 
Table 2 Least-square mean with $95 \%$ confidence interval (backtransformed, where necessary), and $F$ ratio of site, $\log$ position and site-by-log-position interaction effects on log and recovery traits

$n s$ non-significant

$* P<0.05 ; \quad * * P<0.01$; $* * * P<0.001$

${ }^{\mathrm{a}} \log _{10}(x+1)$-transformed

Fig. 1 Site by log position leastsquare means and standard errors for log traits (back-transformed, where necessary). The lower log is shown in grey and the upper log in white. The species (Eucalyptus nitens, Nit; or E. globulus, Glob), silvicultural regime (thinned and pruned, $T h \& P r$ ), average annual rainfall and age at felling (years) are shown for each site

(Strathblane, St; Geeveston, Ge; Florentine, $\mathrm{Fl}$; Deans Marsh, De; Orford, $O r$ and Mumbannar, $M u$ ) at the bottom of the panel. $Y$ axis labels are given in the graph titles. Sites with common letters were not significantly different at $P<0.05$ following a TukeyKramer adjustment for multiple comparisons

\begin{tabular}{|c|c|c|c|c|}
\hline & $\begin{array}{l}\text { Least-square mean } \\
(95 \% \mathrm{CI})\end{array}$ & Site & $\begin{array}{l}\log \\
\text { position }\end{array}$ & $\begin{array}{l}\text { Site by } \log \\
\text { position }\end{array}$ \\
\hline \multicolumn{5}{|l|}{ Log traits } \\
\hline $\operatorname{SEDUB}(\mathrm{mm})^{\mathrm{a}}$ & $272(265-280)$ & $19.0^{* * *}$ & $605.0 * * *$ & $7.4^{* *}$ \\
\hline Sweep $(\mathrm{mm})^{\mathrm{a}}$ & $14.1(13.0-15.4)$ & $5.5^{* * *}$ & $114.9 * * *$ & $1.6 \mathrm{~ns}$ \\
\hline Taper $\left(\mathrm{mm} \mathrm{m}^{-1}\right)^{\mathrm{a}}$ & $9.1(8.4-10.0)$ & $3.5^{* *}$ & $378.6^{* * *}$ & $2.1 \mathrm{~ns}$ \\
\hline Out-of-roundness & $9.00(8.45-9.54)$ & $5.5^{* * *}$ & $28.7 * * *$ & $4.4^{* *}$ \\
\hline End splitting ${ }^{\mathrm{a}}$ & $3.15(2.73-3.61)$ & $9.9^{* * *}$ & $0.1 \mathrm{~ns}$ & $3.0^{*}$ \\
\hline $\mathrm{MOE}_{\text {dyn }}(\mathrm{MPa})$ & $\begin{array}{l}15,264(14,922- \\
15,606)\end{array}$ & $12.6^{* * *}$ & $178.6^{* * *}$ & $5.7 * * *$ \\
\hline \multicolumn{5}{|l|}{ Recovery traits } \\
\hline Peelable billet volume (\%) & $77.2(76.3-78.1)$ & $3.5^{* *}$ & $16.4 * * *$ & $1.8 \mathrm{~ns}$ \\
\hline Recovered green veneer $(\%)$ & $77.6(74.9-80.3)$ & $0.2 \mathrm{~ns}$ & $8.2 * *$ & $0.7 \mathrm{~ns}$ \\
\hline Roundup loss (\%) & $18.5(17.7-19.3)$ & $3.2^{*}$ & $24.1 * * *$ & $2.1 \mathrm{~ns}$ \\
\hline $\begin{array}{l}\text { Core diameter (binary: target-size }=0 \text {, } \\
\text { over-sized }=1 \text { ) }\end{array}$ & $0.857(0.525-1.19)$ & $3.55^{* *}$ & $1.19 \mathrm{~ns}$ & $0.5 \mathrm{~ns}$ \\
\hline
\end{tabular}
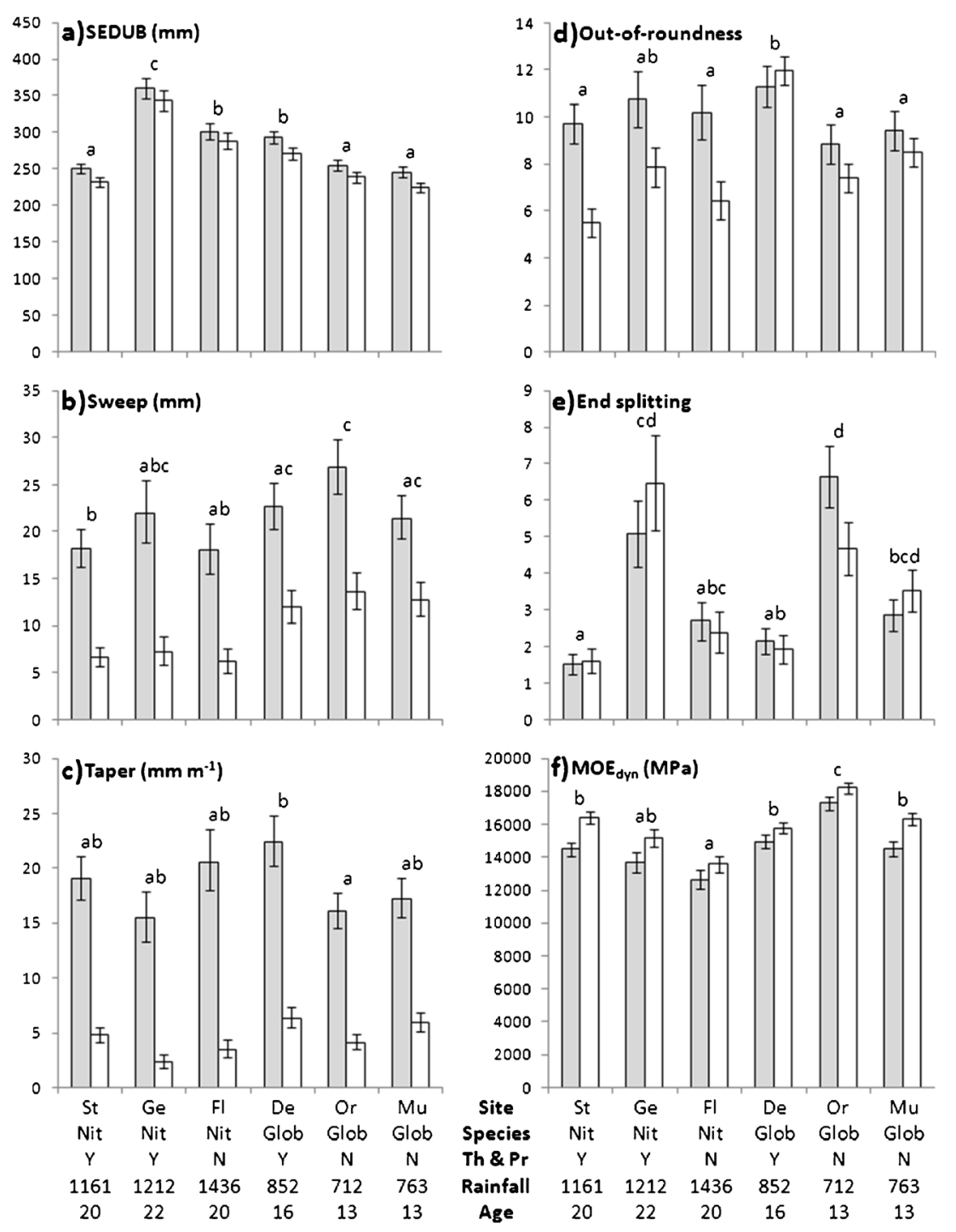
Table 3 Simple linear regression parameter estimates based on non-standardised data.

Explanatory variable Response variable (recovery trait)

(log trait)

\begin{tabular}{|c|c|c|c|c|c|c|c|c|c|}
\hline \multirow[t]{2}{*}{ og } & \multicolumn{3}{|c|}{ Peelable billet volume (\%) } & \multicolumn{3}{|c|}{ Recovered green veneer $(\%)$} & \multicolumn{3}{|c|}{ Roundup loss (\%) } \\
\hline & Intercept & Slope & $R^{2}(\%)$ & Intercept & Slope & $R^{2}(\%)$ & Intercept & Slope & $R^{2}(\%)$ \\
\hline $\operatorname{SEDUB}(\mathrm{mm})^{\mathrm{a}}$ & $68.4(14.01)$ & $3.53(5.784) \mathrm{ns}$ & 0.2 & $80.0(15.18)$ & $-1.58(6.261) \mathrm{ns}$ & 0.0 & $-2.4(12.60)$ & $8.66(5.196) \mathrm{ns}$ & 1.4 \\
\hline Sweep $(\mathrm{mm})^{\mathrm{a}}$ & $85.7(1.77)$ & $-7.38(1.438)^{* * *}$ & 11.7 & $81.0(2.05)$ & $-4.05(1.669) \mathrm{ns}$ & 2.9 & $10.0(1.62)$ & $7.23(1.319)^{* * *}$ & 13.1 \\
\hline Taper $\left(\mathrm{mm} \mathrm{m}^{-1}\right)^{\mathrm{a}}$ & $81.2(1.35)$ & $-4.16(1.252)^{* *}$ & 5.3 & $80.0(1.47)$ & $-3.76(1.366)^{*}$ & 3.7 & $13.9(1.20)$ & $4.65(1.116)^{* * *}$ & 8.0 \\
\hline Out-of-roundness & $83.4(1.06)$ & $-0.72(0.109)^{* * *}$ & 18.1 & $82.3(1.20)$ & $-0.68(0.124)^{* * *}$ & 13.0 & $12.2(0.96)$ & $0.71(0.099)^{* * *}$ & 20.8 \\
\hline End splitting $^{\mathrm{a}}$ & $77.1(1.03)$ & $-0.28(1.539) \mathrm{ns}$ & 0.0 & $75.5(1.14)$ & $1.29(1.703) \mathrm{ns}$ & 0.3 & - & - & - \\
\hline $\mathrm{MOE}_{\text {dyn }}(\mathrm{KPa})$ & $78.4(3.11)$ & $-0.10(0.198) \mathrm{ns}$ & 0.1 & $74.8(3.44)$ & $0.09(0.219) \mathrm{ns}$ & 0.1 & - & - & - \\
\hline
\end{tabular}

Standard errors are enclosed in parentheses and Bonferroni corrected significance level of the slopes from zero are shown, along with the coefficient of determination $\left(R^{2}\right)$ expressed as a percentage. Dashes indicate parameters that were not estimated as there was no a priori expectation that the explanatory variable should explain variation in the response variable

$n s$ non-significant

$* P<0.05 ; * * P<0.01 ; * * * P<0.001$ after Bonferroni correction

${ }^{\mathrm{a}} \log _{10}(x+1)$-transformed

Within sites and log positions (i.e. using standardised data), only out-of-roundness explained significant variation in peelable billet volume, recovered green veneer and roundup loss $(P<0.001)$. The amount of variation in recovery traits explained by out-of-roundness within sites and $\log$ positions was less than that explained across sites and $\log$ positions $\left(R^{2}=10.7 \%\right.$ for peelable billet volume, $9.8 \%$ for recovered green veneer and $10.2 \%$ for roundup loss).

A significant difference between the mean SEDUB of $\log$ with a target-sized residual core and $\operatorname{logs}$ with an over-sized residual core was observed $(P=0.012)$, with over-sized logs having a greater SEDUB. No significant difference between means was evident for end splitting or $\mathrm{MOE}_{\mathrm{dyn}}$.

\section{Discussion}

\subsection{Post-felling log traits}

The selected sites encompassed a range of environments, management regimes, harvest ages, species (E. globulus and E. nitens) and other factors (Online Resource 1). Any one of, or an interaction among, these factors could explain differences in log and recovery traits observed among sites. Appropriately designed and replicated trials are required to verify the cause of differences in log and recovery traits observed among sites in the current study. Clear difference among sites in SEDUB (Fig. 1a, Table 2) reflected these differences in site characteristics. Of the log traits examined, SEDUB is the most easily manipulated through plantation genetics, site selection, management, harvest age or post-harvest segregation. In the current study, trees were selected at random, within size and quality constraints, at each site. However, in commercial operations, trees and logs can be segregated post-felling for different markets. The ranking of sites was stable, regardless of $\log$ position, indicating that the significant site by $\log$ position interaction effect for SEDUB was primarily driven by differences in scale among log positions and/or sites.

The observation that E. globulus sites exhibited greater sweep than the E. nitens sites is in keeping with anecdotal observations by forest managers and researchers (Potts et al. 2011). E. nitens is generally regarded as having straight stems, whereas E. globulus tends to exhibit sinuosity in stem form (Blackburn et al. 2013).

It is possible that the significant difference observed in taper between the Deans Marsh and Orford sites was a result of thinning at Deans Marsh. Thinning tends to disproportionately increase diameter relative to height (Beadle et al. 2011). Extreme butt sweep was not evident at any of the sites at the time of felling and the greater level of sweep and taper observed in the lower log was most likely due to buttressing, despite the removal of the lower $0.5 \mathrm{~m}$ of the stem.

Debarking at the Deans Marsh site revealed substantial bumps on the surface of logs, which was reflected in the high degree of out-of-roundness at this site. It is likely that these bumps were the result of pruning and subsequent slow growth. After final pruning in 2003, the Deans Marsh site experienced a series of below-average rainfall years $(665 \mathrm{~mm}$ in 2004, $709 \mathrm{~mm}$ in 2005, $474 \mathrm{~mm}$ in 2006 recorded at the site) which almost certainly impacted on growth and the rate and process of branch occlusion of large branch stubs. At the time of roundup, the bumps were confirmed to be associated with occluded knots. Observations at peeling also indicated that some pruned branches were beyond the recommended 
size for pruning (Pinkard et al. 2004) and many exhibited necrosis and decay. Such deformities were not prevalent at either of the E. nitens pruned sites, Strathblane and Geeveston. These factors are likely to explain the atypical results from the Deans Marsh site for out-of-roundness and other log and recovery traits (Figs. 1 and 2).

The most noteworthy difference between sites in end splitting was that between Strathblane and Geeveston. Both Strathblane and Geeveston were E. nitens, managed under similar thinning and pruning regimes and harvested at a similar age. However, the Geeveston site clearly exhibited a greater level of end splitting, possibly due to the relatively late and heavy thinning performed at this site and subsequent expression of high growth stresses, low taper, rapid growth and large diameters (Okuyama et al. 2004; Beadle et al. 2011; Kubler 1988). Geeveston was also a far more productive site than Strathblane, which was reflected in growth rate and the size of logs extracted from the site. The difference in end splitting in the lower log between Orford and Mumbannar was also noteworthy. Both of these sites were E. globulus, managed under similar pulpwood silvicultural regimes, harvested at a similar age and yielded logs of similar diameter. Orford was the only site at which trees were felled and debarked using a machine (Online Resource 1) and it is possible that, in this study, machine harvesting exacerbated splitting despite appearing to be more gentle and controlled. The relationships among silviculture, site productivity, harvesting method and splitting and the implications for E. globulus and E. nitens plantation management and processing require further investigation.

Modulus of elasticity is known to increase with cambial and apical age and, accordingly, log height in eucalypts (Medhurst et al. 2012), which was reflected in the findings of this study. Of the E. nitens sites, the thinned and pruned stands exhibited greater $\mathrm{MOE}_{\mathrm{dyn}}$ than the Florentine site. The Strathblane and Florentine sites were both of a similar age and it is possible that this difference in $\mathrm{MOE}_{\mathrm{dyn}}$ was caused by silvicultural differences (Beadle et al. 2011). Species differences across these sites were confounded with harvest age and silvicultural differences and the finding that older thinned and pruned E. nitens sites have comparable $\mathrm{MOE}_{\mathrm{dyn}}$ to E. globulus sites, which is generally regarded as having superior stiffness to $E$. nitens, is encouraging for E. nitens growers. By delaying the harvest of their resource, they could potentially meet the requirements of structural products for which the species was previously considered unsuitable (Farrell et al. 2011). Of the E. globulus sites, Deans Marsh was thinned and pruned and yet had a lower $\mathrm{MOE}_{\mathrm{dyn}}$ than the younger Orford site, which likely reflects the high levels of decay observed in logs from the Deans Marsh site and, potentially, a higher proportion of low-MOE corewood resulting from early thinning. However, the difference in $\mathrm{MOE}_{\text {dyn }}$ between Orford and Mumbannar, which were both E. globulus, unthinned and unpruned,

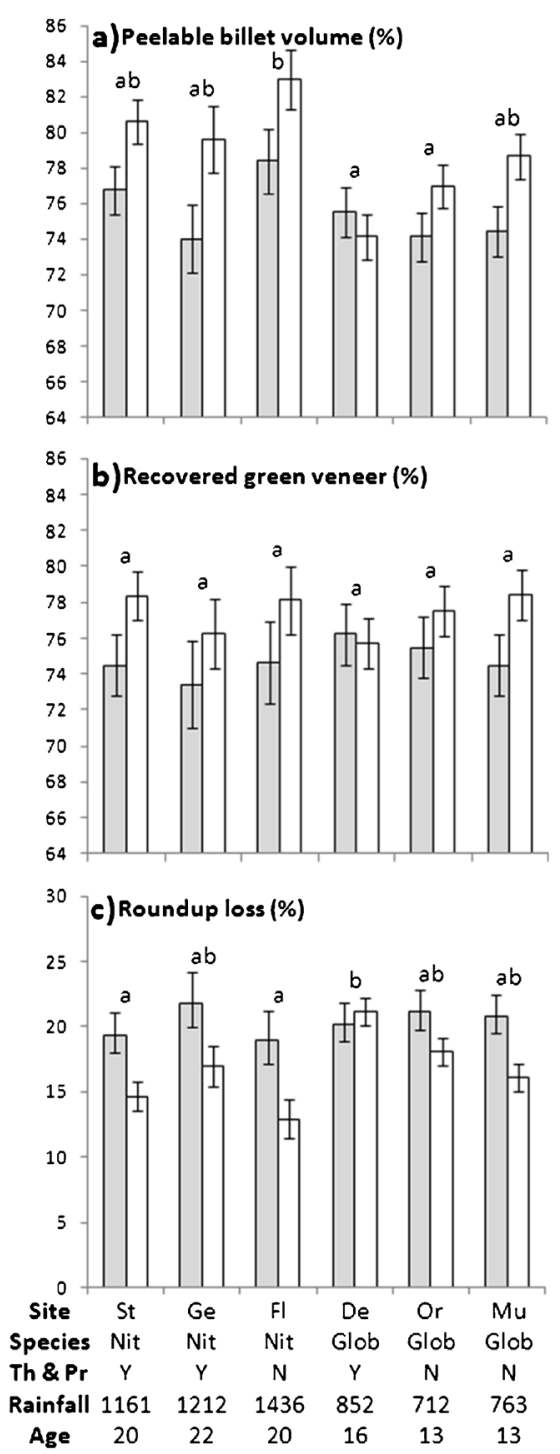

Fig. 2 Site by log position least-square means and standard errors for peelable billet volume, recovered green veneer and roundup loss. The lower log is shown in grey and the upper log in white. The species (Eucalyptus nitens, Nit; or E. globulus, Glob), silvicultural regime (thinned and pruned, $T h \& P r$ ), average annual rainfall and age at felling (years) are shown for each site (Strathblane, St; Geeveston, Ge; Florentine, $\mathrm{Fl}$; Deans Marsh, De; Orford, Or and Mumbannar, $\mathrm{Mu}$ ) at the bottom of the panel. $Y$ axis labels are given in the graph titles. Sites with common letters were not significantly different at $P<0.05$ following a TukeyKramer adjustment for multiple comparisons

harvested at a similar age and yielded logs of similar diameter, is more difficult to explain. Further investigation of the possible drivers of this difference-genetic, environmental or silvicultural-is warranted.

\subsection{Recovery traits}

The mean peelable billet volume ( $77 \%$ of log volume) and green veneer recovery $(78 \%$ ) were greater than those obtained in past studies of these and other plantation eucalypts 
(Blakemore et al. 2010; Thomas et al. 2009; Luo et al. 2013; McGavin et al. 2014), explained in part at least by the use of a splindless lathe, the relatively large log diameters and the use of different measures of green veneer recovery across studies (McGavin et al. 2014; Luo et al. 2013). However, the lack of a statistical difference among sites for recovered green veneer is difficult to explain given that there was a highly significant difference among sites for peelable billet volume (Table 2). Conceptually, these traits should be equivalent, excluding small amounts of waste veneer disposed of at the initiation and/or cessation of peeling.

Although no statistically significant site by log position interaction effect was evident for any log recovery trait, there was generally a greater difference between the upper and lower $\log$ at the E. nitens sites than at the E. globulus sites, likely reflecting the same trend observed in out-of-roundness. In general, peelable billet volume and recovered green veneer was greater in the upper log than the lower log. However, the ranking of the upper and lower log was aberrant at the Deans Marsh site, also reflecting the trend observed in out-ofroundness and the presence of large bumps over occluded pruned knots. Anecdotally, bumps were more prevalent in the upper $\log$ than the lower $\log$ and resulted in the need for the removal of a greater proportion of wood during roundup. Deans Marsh also had the overall lowest peelable billet volume (Fig. 2a) and greatest roundup loss (Fig. 2c) as well as a large proportion of over-sized residual cores, attributable to the large amount of decay observed in logs from this site.

The greater recovery in the smaller-diameter upper logs (Fig. 2) and the fact that SEDUB did not explain significant levels of variation in recovery traits (Table 3 ) contradict some past studies (Thomas et al. 2009; Blakemore et al. 2010). However, in our study, there was a relatively small difference in diameter between the upper and lower log and relatively large differences in other log characteristics, most notably outof-roundness, sweep and taper (Fig. 1). Luo et al. (2013) also noted that decreases in diameter with height did not result in decreased green recoveries and attributed this to the overriding impact of greater sweep and taper in lower logs.

Based on our study, the measurement of the log traits SEDUB, sweep, taper, out-of-roundness, end splitting and $\mathrm{MOE}_{\mathrm{dyn}}$ does not represent a precise or practical means of estimating green veneer recovery at the log level for research or operational purposes. However, the amount of variation in recovery traits explained by measurements made on logs was substantially lower than in a study of diverse hybrid and pure species clones by Luo et al. (2013), in which nearly $80 \%$ of variation in recovery in the lower log was explained by a combination of sweep, taper and circularity. Possible explanations for this difference across studies include the larger SEDUB of logs in the current study, species differences across studies and the fact that measurements by Luo et al. (2013) were made directly on 1.3-m billets, rather than on 2-m logs prior to docking. It is also noteworthy that the production system in the current study was unique to this research-scale study. Under an operational production system, a stronger relationship between log traits and green recovery might be observed. Furthermore, at the site level, the site with the greatest out-of-roundness, Deans Marsh, exhibited the lowest peelable billet volume, hinting that it might be possible to develop tools to classify plantation coupes/estates according to green veneer recovery predicted from measurements made on a small sample of standing trees. Accordingly, an improved understanding of the standing-tree traits that affect green veneer recovery and means of manipulating these traits through genetics, site selection, management or log segregation could increase resource value and efficiency of use.

The significant difference in SEDOB between billets with over-sized and target-sized residual cores could have been due to a relationship between tree diameter (a function of growth rate and harvest age) and other traits affecting residual core diameter, such as wood properties, branching characteristics and decay. However, it is also possible that the difference was driven by the characteristics of one or more individual sites. For example, the Geeveston site had the largest diameter logs and the highest proportion of over-sized residual cores and this high proportion of over-sized cores might have been due to an unknown but inherent characteristic of this site. Although the Geeveston site also had the greatest log end splitting, which might be expected to adversely affect residual core diameter, there was no significant difference in log end splitting between logs with over-sized residual cores and logs with target-sized residual cores.

\section{Conclusion}

Temperate plantation eucalypts can yield high levels of green veneer recovery. Differences in percentage peelable billet volume, percentage roundup loss and residual core were evident among plantation sites, despite their being no discernable differences among sites in percentage recovered green veneer volume. The smaller-diameter upper log exhibited greater green recovery than the lower (butt) log, possibly due to greater sweep, taper and out-of-roundness in the lower log. Differences among sites for traits measured on logs were evident and, in the case of dynamic modulus of elasticity, alluded to differences in wood quality among sites. At the individual log level, a significant proportion of variation in recovery traits was explained by traits measured on logs, most notably out-of-roundness. Green veneer recovery is only the first step in the commercial production of veneer and veneerbased engineered wood products, and further research into veneer grade recovery and utility after drying is required to further guide decisions on species selection, site selection, forest management and product use. 
Acknowledgments We acknowledge Forestry Tasmania (FT), Australian Bluegum Plantations (ABP), New Forests, PF Olsen and David Swann for the assistance in project planning, access to sites, the provision of trees and staff, tree felling, and log transport; Island Specialty Timbers (IST) and ABP for use of their log yards, and log handling; and Austral Plywoods for peeling large-diameter logs. Specifically, we thank Mark Hunt (NCFFI and UTAS), Chris Emmett (IST), Peter Wass, Crispen Marunda, Kristen Dransfield, Matt McCormic, Mitchell Fulford, Paul Adams, Rowan Eiszele, Shane Burgess (FT), Phil Mason and Christian Hong-Tan (New Forests), Stephen Rymer and Noel Bull (PF Olsen), Nigel Miller and Paddy Noonan (Forestech Management), Mark Diedrichs, Alan Rossouw, Simon Malseed (ABP), Chris Harwood (CSIRO), Rowan Reid and staff at the Queensland Department of Agriculture, Fisheries and Forestry Salisbury Research Centre for their technical and/or professional assistance.

Funding We thank the National Centre for Future Forest Industries (NCFFI) for funding.

\section{References}

Arnold RJ, Xie YJ, Midgley SJ, Luo JZ, Chen XF (2013) Emergence and rise of eucalypt veneer production in China. Int For Rev 15:33-47

Beadle C, Medhurst J, Forrester D (2011) Linking silvicultural management to solid-wood values. In: Walker J (ed) Developing a eucalypt resource: learning from Australia and elsewhere. Wood Technology Research Centre, University of Canterbury, Christchurch, pp 77-92

Blackburn D, Farrell R, Hamilton M, Volker P, Harwood C, Williams D, Potts B (2012) Genetic improvement for pulpwood and peeled veneer in Eucalyptus nitens. Can J For Res 42:1724-1732

Blackburn DP, Hamilton MG, Harwood CE, Baker TG, Potts BM (2013) Assessing genetic variation to improve stem straightness in Eucalyptus globulus. Ann For 70:461-470

Blakemore P, Morrow A, Washusen R, Harwood C, Wood M, Ngo D (2010) Evaluation of thin-section quarter-sawn boards and rotary veneer from plantation-grown Eucalyptus nitens. vol Technical Report 202. Cooperative Research Centre for Forestry, Hobart

Brancheriau L, Bailleres H (2002) Natural vibration analysis of clear wooden beams: a theoretical review. Wood Sci Technol 36:347365. doi:10.1007/s00226-002-0143-7

Downes G, Worledge D, Schimleck L, Harwood C, French J, Beadle C (2006) The effect of growth rate and irrigation on the basic density and kraft pulp yield of Eucalyptus globulus and E. nitens. N Z J For Sci 57:13-22

Farrell R, Blum S, Williams D, Blackburn D (2011) The potential to recover higher value veneer products from fibre managed plantation eucalypts and roaden market opportunities for this resource: part A. Forest \& Wood Products Australia, Melbourne

Kibblewhite RP, Johnson BI, Shelbourne CJA (2000) Kraft pulp qualities of Eucalyptus nitens, E. globulus, and E. maidenii, at ages 8 and 11 years. N Z J For Sci 30:447-457

Kubler H (1988) Silvicultural control of mechanical stresses in trees. Can J For Res 18:1215-1225

Luo JZ, Arnold R, Ren SQ, Jiang Y, Lu WH, Peng Y, Xie YJ (2013) Veneer grades, recoveries, and values from 5-year-old eucalypt clones. Ann For Sci 70:417-428. doi:10.1007/ s13595-013-0268-x
McGavin RL, Bailleres H, Lane F, Blackburn D, Vega M, Ozarska B (2014) Veneer recovery analysis of plantation eucalypt species using spindleless lathe technology. Bioresources 9:613-627

McKinley RB, Shelbourne CJA, Low CB, Penellum B, Kimberley MO (2002) Wood properties of young Eucalyptus nitens, E. globulus, and E. maidenii in Northland, New Zealand. N Z J For Sci 32:334 356

Medhurst J, Downes G, Ottenschlaeger M, Harwood C, Evans R, Beadle C (2012) Intra-specific competition and the radial development of wood density, microfibril angle and modulus of elasticity in plantation-grown Eucalyptus nitens. Trees Struct Funct 26:17711780. doi:10.1007/s00468-012-0746-Z

Mohammed C, Battaglia M, Wardlaw T, Smith A, Pinkard E, Glen M, Tommerup I, Potts B, Vaillancourt R (2003) Mycosphaerella leaf diseases of temperate eucalypts around the southern pacific rim. $\mathrm{NZ}$ J For Sci 33:362-372

Okuyama T, Doldan J, Yamamoto H, Ona T (2004) Heart splitting at crosscutting of eucalypt logs. J Wood Sci 50:1-6. doi:10.1007/ s10086-003-0533-y

Pinkard EA, Mohammed C, Beadle CL, Hall MR, Worledge D, Mollon A (2004) Growth responses, physiology and decay associated with pruning plantation-grown Eucalyptus globulus Labill. and E. nitens (Deane and Maiden) Maiden. For Ecol Manag 200:263277

Potts B, Hamilton M, Blackburn D (2011) Genetics of eucalypts: traps and opportunities. In: Walker J (ed) Developing a eucalypt resource: learning from Australia and elsewhere. Wood Technology Research Centre, University of Canterbury, Christchurch, pp 1-26

Shi S, Walker J (2006) Wood-based composites: plywood and veneer-based products. In: Walker JCF (ed) Primary wood processing: principles and practice, 2 nd edn. Springer, Dordrecht, pp 391-426

Thomas D, Joe B, Austin S, Henson M (2009) Characterisation of plywood properties manufactured from plantation grown eucalypts. Forest \& Wood Products Australia, Melbourne

Wardlaw T (2011) A climate analysis of the current and potential future Eucalyptus nitens and E. globulus plantation estate on Tasmanian State forest. Tasforests 19:17-27

Warensjo M, Rune W (2004) Stem straightness and compression wood in a 22-year-old stand of container-grown Scots pine trees. Silva Fenn 38:143-153

Washusen R (2011) Processing plantation grown Eucalyptus globulus and Eucalyptus nitens for solid wood products - is it viable? Cooperative Research Centre for Forestry, Hobart

Washusen R, Harwood C, Morrow A, Northway R, Valencia JC, Volker P, Wood M, Farrell R (2009) Pruned plantation-grown Eucalyptus nitens: effect of thinning and conventional processing practices on sawn board quality and recovery. $\mathrm{N} \mathrm{Z} \mathrm{J}$ For Sci 39:39-55

Wolfinger R, Chang M (1995) Comparing the SAS GLM and MIXED procedures for repeated measures. In: Proceedings of the Twentieth Annual SAS Users Group Conference, Cary, NC. SAS Institute Inc

Wood MJ, McLarin ML, Volker PW, Syme M (2009) Management of eucalypt plantations for profitable sawlog production in Tasmania, Australia. Tasforests 18:117-130

Yang JL (2005) The impact of log-end splits and spring on sawn recovery of 32-year-old plantation Eucalyptus globulus Labill. Holz Roh Werkst 63:442-448. doi:10.1007/s00107-005-0035-2 